
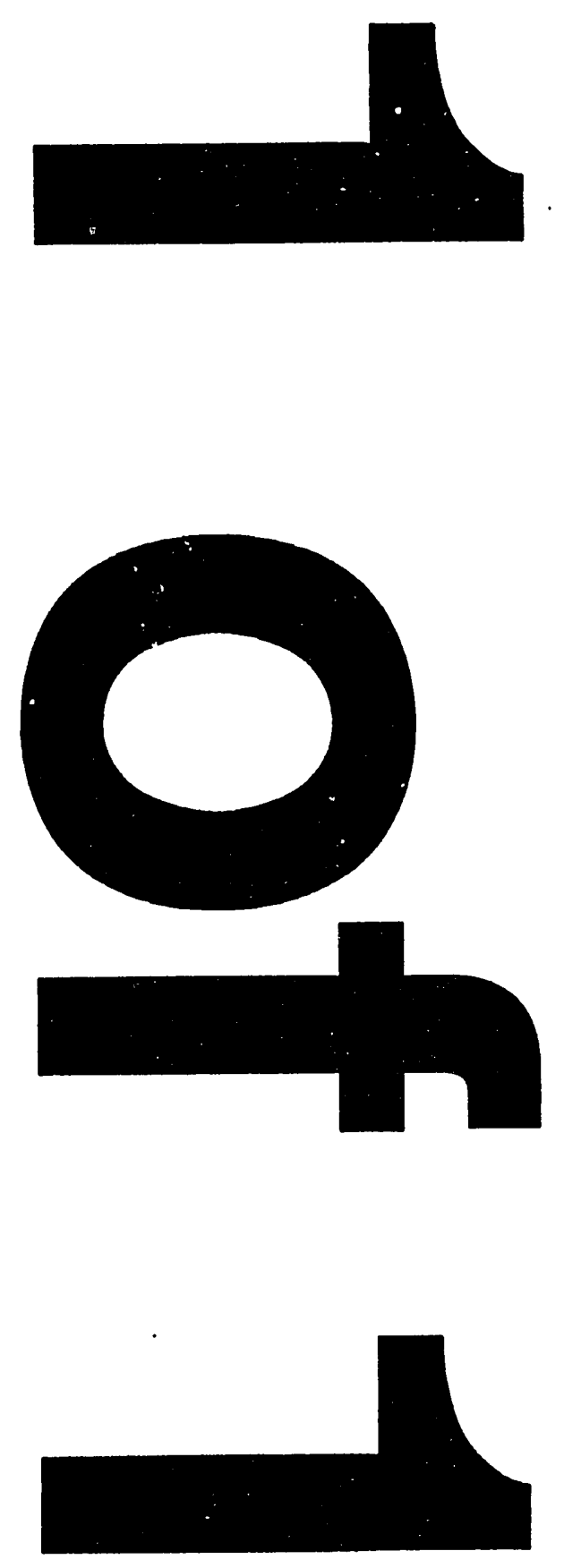
DIELECTRIC AND ABSORBATE EFFECTS ON THE OPTICAL PROPERTIES OF PHOSPHAZENES

\author{
K. F. Ferris \\ G. J. Exarhos \\ Y. Morita \\ W. D. Samuels
}

November - December 1993

Presented at the

1993 Fall Meeting

November 29 - December 3, 1993

Boston, Massachusetts

Work supported by

the U.S. Department of Energy

under Contract DE-ACO6-76RLO 1830

\author{
Pacific Northwest Laboratory \\ Richland, Washington 99352 \\ DISCLAIMER
}

\begin{abstract}
This report was prepared as an account of work sponsored by an agency of the United States Government. Neither the United States Government nor any agency thereof, nor any of their employees, makes any warranty, express or implied, or assumes any legal liability or responsibility for the accuracy, completeness, or usefulness of any information, apparatus, product, or process disclosed, or represents that its use would not infringe privately owned rights. Reference herein to any specific commercial product, process, or service by trade name, trademark, manufacturer, or otherwise does not necessarily constitute or imply its endorsement, recommendation, or favoring by the United States Government or any agency thereof. The views and opinions of authors expressed herein do not necessarily state or reflect those of the United States Government or any agency thereof.
\end{abstract}




\title{
DIELECTRIC AND ABSORBATE EFFECTS ON THE OPTICAL PROPERTIES OF PHOSPHAZENES
}

KIM F. FERRIS, W.D. SAMUELS, Y. MORITA AND G.J. EXARHOS

Pacific Northwest Laboratory, Materials and Chemica'! Sciences Center, P.O. Box 999, Richiand, WA 99352

\begin{abstract}
The optical response of polyphosphazenes can be directly related to the $\pi$ (c.ut-of-plane) and $\pi$ ' (in-plane) bonding interactions intrinsic to the electronic structure of these materials. Altering this structure either by hydrogen bonding or absorbate effects affects both the linear and nonlinear optical susceptibilities. In this paper, we have performed electronic structure calculations on the cyclic molecules, $\mathrm{P}_{3} \mathrm{~N}_{3}\left(\mathrm{NHCH}_{3}\right)_{6}, \mathrm{P}_{3} \mathrm{~N}_{3}\left(\mathrm{SCH}_{3}\right)_{6}$, $\mathrm{P}_{3} \mathrm{~N}_{3}\left(\mathrm{OCH}_{3}\right)_{6}$ and $\mathrm{P}_{4} \mathrm{~N}_{4}\left(\mathrm{NHCH}_{3}\right)_{8}$ as model systems for the polymer. Charge distribution arguments are discussed to explain the influence of a polarizing electric field on the $\pi$ bonding systems, and are used to suggest methods to enhance their nonlinearities.
\end{abstract}

\section{INTRUDUCTION}

Although the applications of nonlinear optical materials have increased greatly in the last ten years, further progression will require both new materials and a more basic means to control their nonlinearities. The understanding of the relationship between electronic structure and the second hyperpolarizability $(\gamma)$ is still very limited; the point the know that larger conjugated networks in organic polymers lead to larger hyperpolarizabilities. However, this generality has not extended to their inorganic analogs. Inorganic polymers have been used as backbone structures (P-N, Si-O frameworks) to attach and align NLO chromophores, and have recently come under scrutiny as possible NLO materials in their own right [1]. But, recent experimental measurements and modeling surveys of the possible backbone compositions have given a discouraging view for the potential NLO yields from these materials when compared to organic materials [2-3].

Despite the fact that they are also conjugated materials, the apparent source of this inefficiency lies in their chemical bonding. Although there are both $\pi$ (out-of-plane) and $\pi$ (in-plane) bonding systems, the electronic charge in phosphonitrilic materials is largely localized on the nitrogen because of the electronegativity differences between phosphorus and nitrogen [4]. The magnitude of the $\pi$ electron density on the phosphorus can be affected by the electronegativity of the substituents and the P-N-P bond angle [5], which in turn controls the delocalization of the $\pi$ electrons. However, these means do not change the early saturation behavior for phosphonitrilic oligomers [2].

Thus, our aim was to probe the alternative ways to electronically tune these materials. The basis of our approach is to tune particular components of the electronic structure as they relate to nonlinear properties. In previous work, we have used perturbation theory and the sum-over-states formalism to ascertain the critical components to the nonlinear optical properties of phosphonitrilic molecules [2]. In the second hyperpolarizability, the largest terms for $\gamma_{x x x x}$ have the form: $\frac{\left\langle 0\left|\mu_{x}\right| i\right\rangle\left\langle i\left|\mu_{x}\right| i\right\rangle\left\langle i\left|\mu_{x}\right| i\right\rangle\left\langle i\left|\mu_{x}\right| 0\right\rangle}{\left(E_{i}-E_{0}\right)^{3}}$, revealing that the critical terms are the electronic transition energies, and state and transition dipole strengths. Organic molecules, the high hyperpolarizabilities result from high transition dipole strengths originating from $\pi-->\pi^{*}$ transitions. Previous calculations on cyclic 
phosphazenes have shown that the dominant optical characteristics are $n-->\pi^{*}$ electronic transitions, which have notoriously weak transition strengths, and a large $\Delta \mathrm{E}_{\text {trans }}$ [5]. Applying the perturbative method to the linear phosphonitrilic system of $\mathrm{F}_{3} \mathrm{P}\left(\mathrm{NPF}_{2}\right) \mathrm{NH}$, we found the largest five contributors to the hyperpolarizability were:

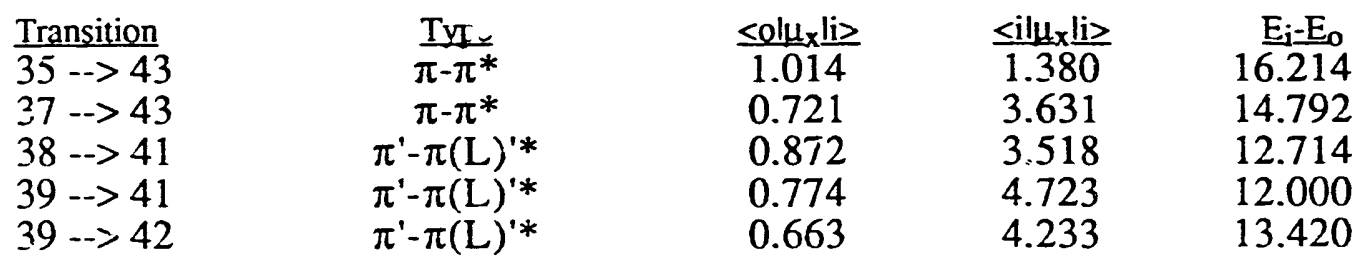

These characteristics would indicate that the phosphonitrilic systems represent special cases of conjugated molecules as their $\pi$ orbital interactions are localized and have high state dipole strengths, but low transition strengths. In this sense our goals are simple, : perturb the electronic structure from its normal gas phase patterns. At the atomistic level, solvent dielectric interactions can alter gas phase bond dipoles and increase delocalization. Absorbate will break gas phase symmetry conditions yhich would reduce transition dipole strengths, and through direct atomic site interaction change site-to-site charge differences. In this paper, we use a combination of experimental and theoretical methods to probe the absorbate and acidity effects on the nonlinear optical properties of phosphonitrilic molecules.

\section{EXPERIMENTAL AND THEORETICAL METHODS}

\section{Computational Model}

Semiempirical valence electron molecular orbital methods were used to evaluate the electronic structure of derivatized phosphonitrilic compounds. All molecular structures were fully force optimized with no geometric constraints other than obvious symmetries. Structural parameters for initial geometries were taken from cvaiiable x-ray crystal structure determinations, whenever possible. Previous studies have shown that MNDO and PM3 Hamiltonians to be highly accurate for the prediction of proton affinities (7.2 $\mathrm{kcal} / \mathrm{mole}$ mean absolute error with systematic tendencies for chemical classes of molecules) [7-8]. Hyperpolarizabilities were calculated by finite field methods using the PM3 Hamiltonian in MOPAC 6.0 (QCPE \#455).

\section{Sample Preparation and Characterization.}

Derivatized phosphazene trimers and tetramers were prepared from synthetic methods in open literature [9]. Reaction products were characterized using $31 \mathrm{P}$ NMR spectra obtained at $121.1 \mathrm{~Hz}$ with a Varian VXR-300 spectrometer and referenced to $85 \% \mathrm{H}_{3} \mathrm{PO}_{4}$. Measured NMR spectra were consistent with published results [8].

Third-order susceptibilities were determined from concentrated phosphazene solutions (10\% wt.) by DFWM measurements [10]. For acidic conditions, the $\mathrm{pH}$ of these solutions was reduced to $\mathrm{pH}=1$ by the addition of concentrated aqueous $\mathrm{HCl}$. For our experiments, the probe beam is recollimated to a $2-\mathrm{mm}$-diameter spot size prior to interaction with the sample, and an intensified gated arraŷ detéctor is used to record simultaneously both the phase conjugate diffracted beam and the incident probe beam intensity for each laser pulse. The measurement is performed in a time-resolved manner by triggering the gate with an appropriately delayed sigrial from the Q-switched Nd:YAG laser $(532 \mathrm{~nm}$ excitation, $8 \mathrm{~ns}$ pulsewidth, 1-40 mJ/pulse). The gate open time was held constant at $18 \mathrm{~ns}$. To reject stray light, a $532 \mathrm{~nm}$ notch filter (NF) was placed in front of the array detector, and allowed only light normal to the array to be transmitted. Data from at least 64 pulses of increasing energy were used to evaluated response relative to the carbon disulfide reference standard. 


\section{RESULTS AND DISCUSSION}

The aim of the current work is to use the combination of experimental and theoretical methods to enhance the nonlinear response of phosphonitrilic systems in a controlled fashion. As a first step, we have experimentally determined the nonlinear response of $\mathrm{N}_{3} \mathrm{P}_{3}\left(\mathrm{NHCH}_{3}\right)_{6}, \mathrm{~N}_{4} \mathrm{P}_{4}\left(\mathrm{NHCH}_{3}\right)_{8}$, and $\left.\mathrm{N}_{3} \mathrm{P}_{3}\left(\mathrm{~N}_{(\mathrm{CH}}\right)_{2}\right)_{6}$ as a $10 \%$ by wit. solution in water and acidic conditions (Table 1). Notably, the relative $\chi^{3}$ for $\mathrm{N}_{3} \mathrm{P}_{3}\left(\mathrm{NHCH}_{3}\right)_{6}$ is over 3 times the original value, and for the corresponding tetramer is over 6 times its free solution value. Both represent dramatic enhancements over earlier reported values for neutral phosphazene species [1], and would form the basis of new strategies for the design on nonlinear inorganic materials.

Table 1 - Relative third-order susceptibilities $\left(\chi^{3}\right)$ for amino-substituted phosphonitrilic molecules determined by DFWM experiment.

$10 \%$ wt. solution

$\mathrm{N}_{3} \mathrm{P}_{3}\left(\mathrm{NHCH}_{3}\right)_{6}$

$\mathrm{N}_{4} \mathrm{P}_{4}\left(\mathrm{NHCH}_{3}\right)_{8}$

$\mathrm{N}_{3} \mathrm{P}_{3}\left(\mathrm{~N}\left(\mathrm{CH}_{3}\right)_{2}\right)_{6}$
$9.458 \times 10^{-5}$

$4.203 \times 10^{-6}$

$3.994 \times 10^{-6}$
$10 \%$ wt. solution

with acid addition

$3.153 \times 10^{-4}$

$2.522 \times 10^{-5}$

Our intital task in modeling these acid/water effects was to determine whether the reactive site was the ring nitrogen or ligand for each of the systems. On a case-by-case basis, a proton was located at each potential atomic site and the geometry was force optimized to determine its heat of formation. Sirce proton interaction by acid reaction or hydrogen bonding is involved for each perturbation, similar considerations should apply for both cases. For proton interaction via hydrogen bonding, we placed a single water molecule within typical hydrogen bonding distance of a ring nitrogen (1.78 $⿱$ ) with its $\mathrm{O}-\mathrm{H}$ bond vector directed towards the nitrogen lone pair. The molecular geometry was subsequently forced optimized, which typically located the water hydrogen atom about $1.65 \AA$ from the nitrogen.

In Table 2, we have listed the comparative heats of formation and proton affinities for the series of protonated phosphonitrilic molecules. Notably, all the phosphonitrilic systems considered here had nonplanar ring confcrmations, with the exception of the charge neutral $\mathrm{N}_{3} \mathrm{P}_{3}\left(\mathrm{~N}\left(\mathrm{CH}_{3}\right)_{2}\right)_{6}$. Ring conformations were typically chair-like as illustrated in Figure 1o betow. The heats of formation for ring protonated phosphazene species are consistently lower for the ligand protonated cases, and their corresponding proton affinities higher. These results are consistent with early experimental measurements by Shaw and coworkers [11] in which they had determined the effective $\mathrm{pKa}$ for this series in aqueous and nonaqueous solutions. Using direct field relationships, they had proposed the ring nitrogen to be most basic. The computational approach allowed us to directly probe this question, and differentiate among the possible protonation sites. The single protonation case is given in detail as the proton affinity for the next reactive site is at least $15 \mathrm{kcal} / \mathrm{mole}$ less energetic for the entire series, and solution concentrations for our experimental section are between 0.25 and $0.35 \mathrm{M}$.

In Tables 3 and 4, we list the predicted nonlinear optical properties for the isolated gas phase molecule and single protonation cases [12]. Ring protonation enhances the $\chi^{3}$ yield in all cases, with an $\sim 50 \%$ increase for our experimentally measured cases. The qualitative indication of an increase in $\chi^{3}$ is viewed as being suitable, especially considering the simplicity of our theoretical models. The quick interpretation of the effect of ring protonation is that it reduces the accumulation of charge on the ring nitrogen atom, making delocalization of P N-P centers more efficient. In previous Huckel calculations on 

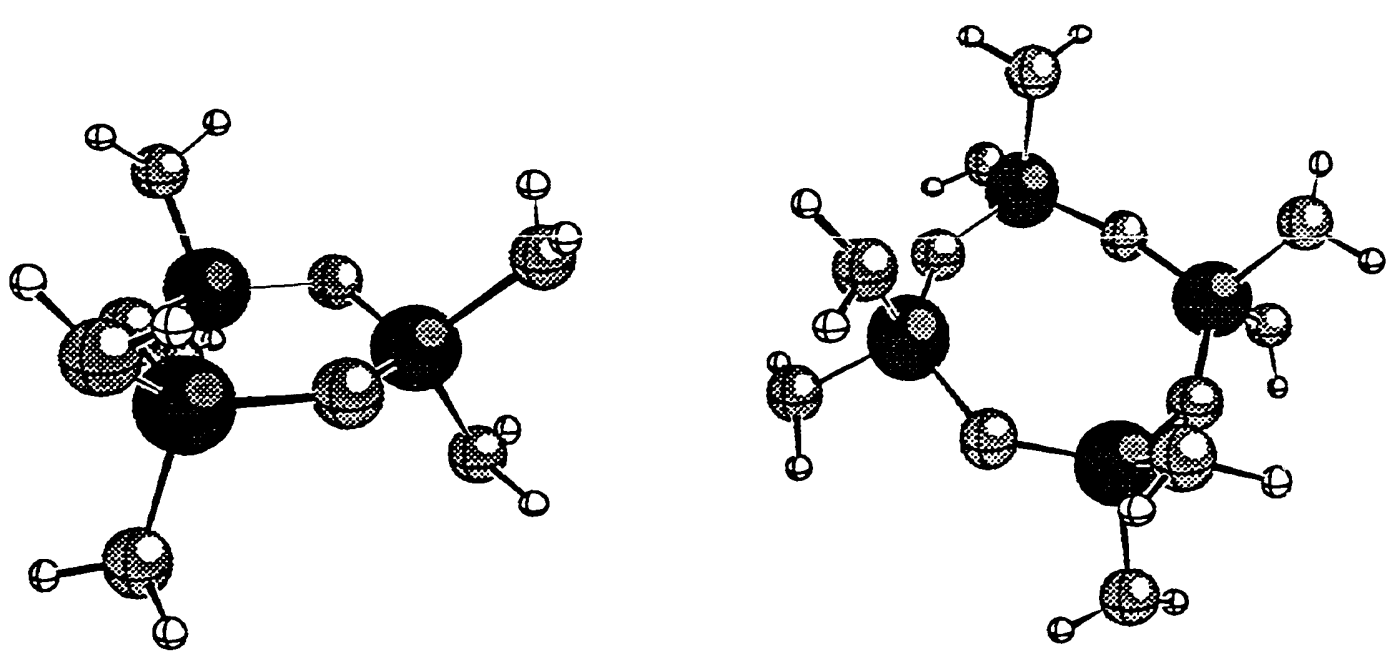

Figure 1 - Molecular Structures of $\mathrm{N}_{3} \mathrm{P}_{3}\left(\mathrm{NH}_{2}\right)_{6}$ and $\mathrm{N}_{4} \mathrm{P}_{4}\left(\mathrm{NH}_{2}\right)_{8}$. Calculations indicate that ring nitrogenous are the site of first protonation.

phosphonitrilic systems, we had noted that the second hyperpolarizability was driven by the charge difference between adjacent centers along the P-N backbone [13]. The effective charges on the nitrogen atoms change from -1.1 to $-0.83-0.87$ consistent with our Huckel arguments.

The effects of hydrogen bonding by water is given in Table 5 . Water enhances the nonlinear response of these molecules, but to a lesser degree than protonation by acids. However, it changes the relative ordering of $-\mathrm{NH}\left(\mathrm{CH}_{3}\right)$ and $-\mathrm{N}\left(\mathrm{CH}_{3}\right)_{2}$ trimer derivatives into agreement with the experimentally measured ordering [9]. Based upon the charge redistribution argument given above; we would expect and have observed negligible charge differences on the nitrogen atoms upon hydrogen bonding. The largest $\Delta \rho$ value for a ring nitrogen in the amino derivatives is 0.04 . We would not consider this value to be significant given the known shortcomings of population analysis schemes to the geometry factors involved with the added coordination. Thus, protonation was a more direct perturbation of the electronic structure than water coordination. We would suggest a largest differential effect among the $-\mathrm{NH}_{2},-\mathrm{NH}\left(\mathrm{CH}_{3}\right)$ and $-\mathrm{N}\left(\mathrm{CH}_{3}\right)_{2}$ trimer derivatives would be ability of ligand nitrogen atoms to donate a hydrogen atom in a hydrogen bonding manner. This atom is within typical hydrogen bonding distances of the water oxygen. Current modeling efforts with larger numbers of water molecules and hydronium ion sources are under way to more closely match our experimental conditions.

\section{SUMMARY}

While the optical response of the framework is sensitive to the ligand electron donation characteristics, protonation of a ring nitrogen or hydrogen bonding to the same site by a water molecule can have profound effects on the nonlinear optical properties. Using the combination of experimental and theoretical methods, we have measured enhanced $\chi^{3}$ yields for some simple phosphonitrilic trimers and established an electronic basis for this effect. While ligands effects have shown to have an important role in the nonlinear optical properties, their effects are secondary to the large enhancements achievable through changes in the charge distribution on the P-N backbone. 
Table 2 - Heats of formation and proton affinities for a series of phosphonitrilic molecules (kcal/mole).

\begin{tabular}{|c|c|c|c|}
\hline Species & Position & $\underline{\Delta \mathrm{H}_{\mathrm{f}}}$ & Proton Affinity \\
\hline$\left[\mathrm{N}_{3} \mathrm{P}_{3}\left(\mathrm{NH}_{2}\right)_{6}\right]^{1+}$ & ring & 21.80 & 245.00 \\
\hline$\left[\mathrm{N}_{3} \mathrm{P}_{3}\left(\mathrm{NH}_{2}\right)_{6}\right]^{1+}$ & ligand & 37.70 & 229.10 \\
\hline$\left[\mathrm{N}_{3} \mathrm{P}_{3}\left(\mathrm{NHCH}_{3}\right)_{6}\right]^{1+}$ & ring & 31.67 & 249.06 \\
\hline$\left[\mathrm{N}_{3} \mathrm{P}_{3}\left(\mathrm{NHCH}_{3}\right)_{6}\right]^{1+}$ & ligand & 52.11 & 228.62 \\
\hline$\left[\mathrm{N}_{3} \mathrm{P}_{3}\left(\mathrm{~N}\left(\mathrm{CH}_{3}\right)_{2}\right)_{6}\right]^{1+}$ & ring & 42.17 & 258.41 \\
\hline$\left[\mathrm{N}_{3} \mathrm{P}_{3}\left(\mathrm{~N}\left(\mathrm{CH}_{3}\right)_{2}\right)_{6}\right]^{1+}$ & ligand & 64.25 & 236.33 \\
\hline$\left[\mathrm{N}_{3} \mathrm{P}_{3}\left(\mathrm{OCH}_{3}\right)_{6}\right]^{1+}$ & ring & -254.97 & 247.14 \\
\hline$\left[\mathrm{N}_{3} \mathrm{P}_{3}\left(\mathrm{OCH}_{3}\right)_{6}\right]^{1+}$ & ligand & -215.09 & 207.25 \\
\hline$\left[\mathrm{N}_{3} \mathrm{P}_{3}\left(\mathrm{SCH}_{3}\right)_{6}\right]^{1+}$ & ring & 106.08 & 235.72 \\
\hline$\left[\mathrm{N}_{3} \mathrm{P}_{3}\left(\mathrm{SCH}_{3}\right)_{6}\right]^{1+}$ & ligand & 125.70 & 216.10 \\
\hline$\left[\mathrm{N}_{4} \mathrm{P}_{4}\left(\mathrm{NH}_{2}\right)_{8}\right]^{1+}$ & ring & -24.65 & 248.10 \\
\hline$\left[\mathrm{N}_{4} \mathrm{P}_{4}\left(\mathrm{NH}_{2}\right)_{8}\right]^{1+}$ & ligand & -14.23 & 237.67 \\
\hline$\left[\mathrm{N}_{4} \mathrm{P}_{4}\left(\mathrm{NHCH}_{3}\right)_{8}\right]^{1+}$ & ring & -7.01 & 251.56 \\
\hline$\left[\mathrm{N}_{4} \mathrm{P}_{4}\left(\mathrm{NHCH}_{3}\right)_{8}\right]^{1+}$ & ligand & 7.92 & 236.63 \\
\hline$\left[\mathrm{N}_{4} \mathrm{P}_{4}\left(\mathrm{~N}\left(\mathrm{CH}_{3}\right)_{2}\right)_{8}\right]^{1+}$ & ring & 1.10 & 253.86 \\
\hline$\left[\mathrm{N}_{4} \mathrm{P}_{4}\left(\mathrm{~N}\left(\mathrm{CH}_{3}\right)_{2}\right)_{8}\right]^{1+}$ & ligand & 20.16 & 234.80 \\
\hline
\end{tabular}

Table 3 - Linear and nonlinear optical constants (esu) for a series of phosphonitrilic molecules.

$\begin{array}{lccc} & \frac{\alpha \times 10^{-23}}{3.537} & \frac{\beta \times 10^{-30}}{-0.125} & \frac{\gamma \times 10^{-36}}{14.12} \\ \mathrm{~N}_{3} \mathrm{P}_{3}\left(\mathrm{NH}_{2}\right)_{6} & 5.110 & -0.821 & 25.30 \\ \mathrm{~N}_{3} \mathrm{P}_{3}\left(\mathrm{NHCH}_{3}\right)_{6} & 6.404 & 0.000 & 26.70 \\ \mathrm{~N}_{3} \mathrm{P}_{3}\left(\mathrm{~N}^{-}\left(\mathrm{CH}_{3}\right)_{2}\right)_{6} & 4.360 & 0.049 & 19.19 \\ \mathrm{~N}_{3} \mathrm{P}_{3}\left(\mathrm{OCH}_{3}\right)_{5} & 8.145 & 0.073 & 44.41 \\ \mathrm{~N}_{3} \mathrm{P}_{3}\left(\mathrm{SCH}_{3}\right)_{6} & & & \\ & 4.974 & 1.906 & 25.57 \\ \mathrm{~N}_{4} \mathrm{P}_{4}\left(\mathrm{NH}_{2}\right)_{8} & 7.089 & 1.766 & 43.09 \\ \mathrm{~N}_{4} \mathrm{P}_{4}\left(\mathrm{NHCH}_{3}\right)_{8} & 9.086 & 0.693 & 52.19 \\ \mathrm{~N}_{4} \mathrm{P}_{4}\left(\mathrm{~N}_{1}\left(\mathrm{CH}_{3}\right)_{2}\right)_{8} & 6.055 & -0.640 & 36.13 \\ \mathrm{~N}_{4} \mathrm{P}_{4}\left(\mathrm{OCH}_{3}\right)_{8} & 11.14 & 0.477 & 82.94 \\ \mathrm{~N}_{4} \mathrm{P}_{4}\left(\mathrm{SCH}_{3}\right)_{8} & & & \end{array}$

Table 4 - Linear and nonlinear optical constants (esu) for a series of phosphonitrilic molecules with a single ring nitrogen protonated.

$\begin{array}{llll} & \frac{\alpha \times 10^{-23}}{3.600} & \frac{\beta \times 10^{-30}}{} & \frac{\gamma \times 10^{-36}}{1.205} \\ \mathrm{~N}_{3} \mathrm{P}_{3}\left(\mathrm{NH}_{2}\right)_{6} & 5.222 & -1.751 & 14.66 \\ \mathrm{~N}_{3} \mathrm{P}_{3}\left(\mathrm{NHCH}_{3}\right)_{6} & 6.559 & -2.608 & 33.03 \\ \mathrm{~N}_{3} \mathrm{P}_{3}\left(\mathrm{~N}_{\left.\left(\mathrm{CH}_{3}\right)_{2}\right)_{6}}\right. & 4.429 & -2.281 & 33.62 \\ \mathrm{~N}_{3} \mathrm{P}_{3}\left(\mathrm{OCH}_{3}\right)_{6} & 8.653 & 3.158 & 24.09 \\ \mathrm{~N}_{3} \mathrm{P}_{3}\left(\mathrm{SCH}_{3}\right)_{6} & 7.211 & -3.947 & 64.11 \\ \mathrm{~N}_{4} \mathrm{P}_{4}\left(\mathrm{NHCH}_{3}\right)_{8} & & & 53.31\end{array}$


Table 5 - Linear and nonlinear optical constants (esu) for a series of phosphonitrilic molecules with a single water molecule absorbed at each ring nitrogen site.

$\begin{array}{llcl} & \frac{\alpha \times 10^{-23}}{4.037} & \frac{\beta \times 10^{-30}}{\gamma \times 136} & \frac{\gamma \times 10^{-36}}{17.45} \\ \mathrm{~N}_{3} \mathrm{P}_{3}\left(\mathrm{NH}_{2}\right)_{6} & 5.668 & -0.039 & 29.01 \\ \mathrm{~N}_{3} \mathrm{P}_{3}\left(\mathrm{NHCH}_{3}\right)_{6} & 6.887 & 0.411 & 26.98 \\ \mathrm{~N}_{3} \mathrm{P}_{3}\left(\mathrm{~N}^{2}\left(\mathrm{CH}_{3}\right)_{2}\right)_{6} & 4.858 & 0.160 & 22.25 \\ \mathrm{~N}_{3} \mathrm{P}_{3}\left(\mathrm{OCH}_{3}\right)_{6} & 3.596 & -0.261 & 46.03 \\ \mathrm{~N}_{3} \mathrm{P}_{3}\left(\mathrm{SCH}_{3}\right)_{6} & 7.958 & -0.750 & 48.57 \\ \mathrm{~N}_{4} \mathrm{P}_{4}\left(\mathrm{NHCH}_{3}\right)_{8} & & \end{array}$

\section{ACKNOWLEDGMENTS}

This work has been supported by the U.S. Department of Energy, Office of Basic Energy Sciences, Materials Sciences Division. The Pacific Northwest Laboratory is operated by Battelle Memorial Institute under Contract DE-AC06-76RLO 1830.

\section{REFERENCES}

[1] G.J. Exarhos and K.M. Crosby, NIST Spec. Pub. 801, Proc. Boulder Damage Symp. 1989, Ed. H.E. Bennett, L.L. Chase, A.H. Guenther, B.E. Newnam, and M.J. Soileau, U.S. Dept. Commerce., p. 324 (1989).

[2] K.F. Ferris and S.M. Risser, NIST Spec. Pub. 801, Proc. Boulder Damage Symp. 1989, Ed. H.E. Bennett, L.L. Chase, A.H. Guenther, B.E. Newnam, and M.J. Soileau, U.S. Dept. Commerce., p. 584 (1989).

[3] K.F. Ferris and S.M. Risser, Mat. Res. Soc. Symp. Proc. Vol. 214: 47 (1991).

[4] K.F. Ferris, P. Friedman, and D.M. Friedrich, Int. J. Quantum Chem 22:207 (1988).

[5] K.F. Ferris and C.B. Duke, Int. J. Quantum Chem. 23: 397 (1989).

[6] K.F. Ferris, A.K. Hansen, and S.M. Risser, Mat. Res. Soc. Symp. Proc. Vol. 173: 683 (1989)

[7] G.P. Ford and J.D. Scribner, J. Comp. Chem. 4, 594 (1983); S. Olivella, F. Urpi and J. Vilarrasa, J. Comp. Chem. 5, 230 (1984).

[8] J.J. Stewart, J. Comp. Chem. 10, 221 (1989)

[9] G.J. Exarhos, W.D. Samuels, and S.D. Burton, Mat. Res. Soc. Symp. Proc. Vol. 244: 269 (1992).

[10] GG.J. Exarhos and W.D. Samuels, Mat. Res. Soc. Symp. Proc. Vol. 175: 95 (1990).

[11] D. Feakins, W.A. Last and R.A. Shaw, J. Chem. Soc. 4464 (1964), D. Feakins, W.A. Last, N. Neemuchwala, and R.A. Shaw, J. Chem. Soc. 2804 (1965).

[12] Optical properties are given in esu on a per molecule basis.

[13] S.M. Risser and K.F. Ferris, Chem. Phys. Lett. 170, 349 (1989). 

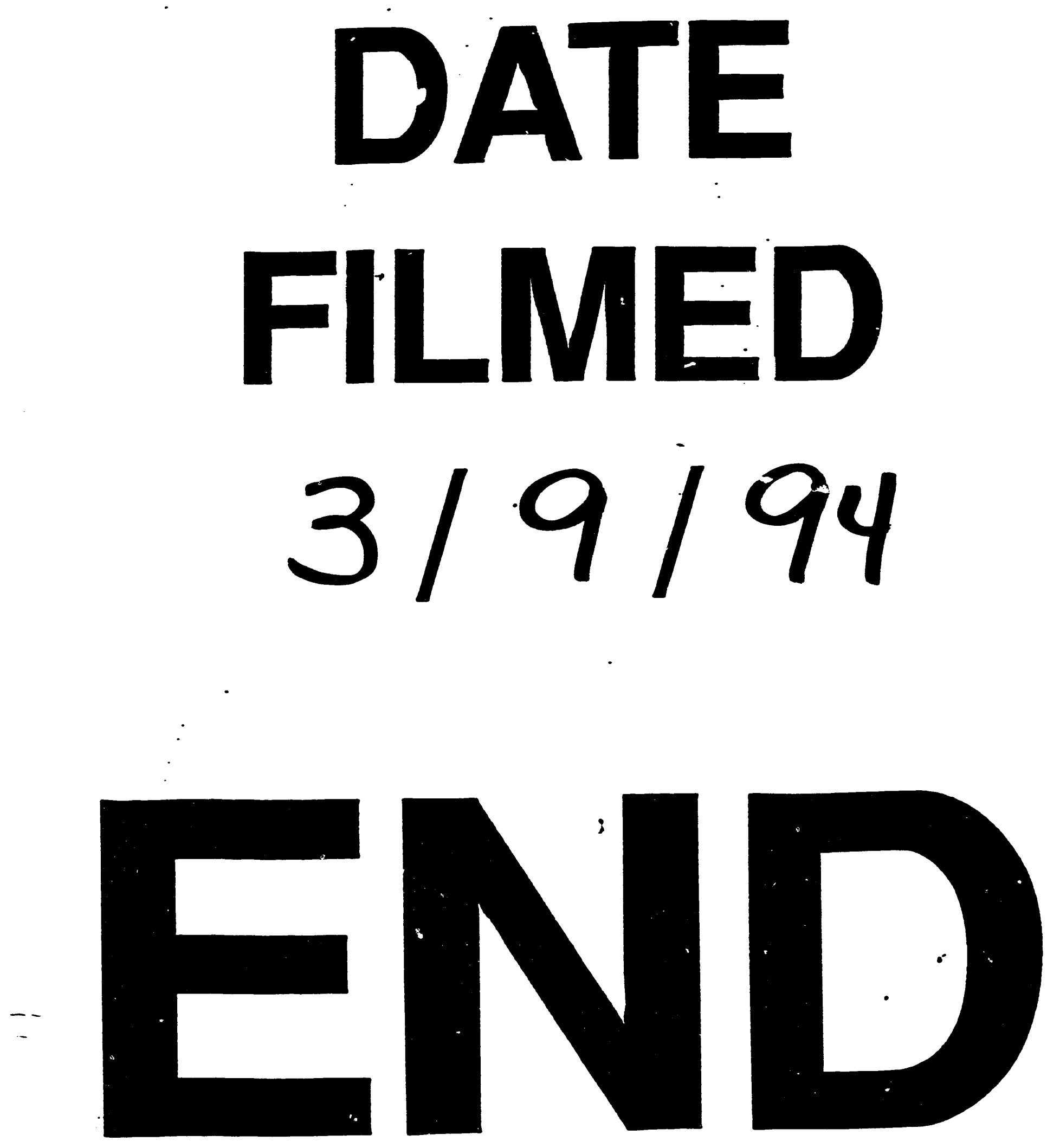